\title{
DESEMPENHO INDIVIDUAL E DE POPULAÇÕES DE PLANTAS DE ARROZ HÍBRIDO EM FUNÇÃO DA QUALIDADE FISIOLÓGICA DAS SEMENTES ${ }^{1}$
}

\author{
FABIO MIELEZRSKI'2, LUIS OSMAR BRAGA SCHUCH³ , SILMAR TEICHERT PESKE ${ }^{3}$, \\ LUÍS EDUARDO PANOZZO ${ }^{4}$, FABRÍCIO BECKER PESKE ${ }^{5}$, RUDINELI RIBEIRO CARVALHO ${ }^{6}$.
}

RESUMO - O trabalho teve por objetivo avaliar o comportamento individual e de populações de plantas de arroz híbrido originadas de sementes de alto e de baixo vigor, dentro de populações que foram constituídas de diferentes combinações de distribuição dessas plantas ao longo da linha de semeadura. O experimento foi conduzido em condições de campo na Universidade Federal de Pelotas, Capão do Leão/RS, constando de cinco tratamentos (proporções de 0, 25, 50, 75 e 100\% de plantas originadas de sementes de alto vigor na população). Para tanto, utilizou-se sementes de arroz do híbrido Avaxi da empresa RiceTec ${ }^{\circledR}$, originadas de dois lotes devidamente caracterizados como alto e baixo vigor. A semeadura de cada lote foi realizada em bandejas distintas com solo como substrato. Após a emergência das plântulas foi realizado um desbaste nas bandejas, retirando as plantas mais precoces no lote de baixo vigor e as plântulas mais tardias no lote de alto vigor, com o propósito de utilizar as plântulas emergidas no dia de maior freqüência de emergência em cada um dos níveis de vigor. O transplante das plantas foi realizado aos 20 dias após a semeadura. Utilizou-se o delineamento experimental de blocos ao acaso com 3 repetições. Avaliou-se: a estatura das plantas aos 60 Dias Após Transplante (DAT), área foliar, número de perfilhos aos 60 DAT, número de panículas por planta aos $115 \mathrm{DAT}$, número de grãos por panícula, número de grãos por planta, e rendimento de grãos por planta. As plantas originadas de sementes de alto vigor apresentaram desempenho superior às plantas provenientes de sementes de baixo vigor para as características avaliadas, independente do sistema de distribuição das plantas ao longo da linha de semeadura. $\mathrm{O}$ uso de sementes de alto vigor no estabelecimento de comunidades de arroz híbrido proporciona acréscimos superiores a $30 \%$ no rendimento de grãos.

Termo para indexação: Oryza sativa, vigor, arranjo.

\section{INDIVIDUAL AND POPULATIONS PERFORMANCE OF HYBRID RICE PLANTS IN FUNCTION OF SEEDS PHYSIOLOGICAL QUALITY}

\begin{abstract}
The work had the objective of evaluating the individual behavior of plants originated from seeds of high and low vigor of hybrid rice, inside of populations and behavior of populations of hybrid rice plants that were constituted by different ratio of plants derived from seeds of high and low physiological quality. The experiment was conducted in the experimental area of the agronomy school. It was used seeds of hybrid rice of the cultivar Avaxi, which belongs to the Ricetec $\AA$, consisting 5 treatments ( ratio of $0,25,50,75$ and $100 \%$ plants originated from seeds of high vigor in the population) including two lots characterized as low and high vigor. After the emergence of the
\end{abstract}

${ }^{1}$ Submetido em 19/08/2007. Aceito para publicação em 25/07/2008. Parte da dissertação de mestrado do primeiro autor que será apresentada à UFPel/ FAEM.

${ }^{2}$ Mestre em Ciência e Tecnologia de Sementes, UFPel/FAEM, fabioagro@ hotmail.com

${ }^{3}$ Professor, Dr., Departamento de Fitotecnia, UFPel/FAEM, Caixa Postal 354, CEP: 96010-900
${ }^{4}$ Mestre em Fitossanidade, UFPel/FAEM, lepanozzo@gmail.com

${ }^{5}$ Mestre em Ciência e Tecnologia de Sementes, UFPel/FAEM, fpeske@ hotmail.com

${ }^{6}$ Mestre em Ciência e Tecnologia de Sementes, UFPel/FAEM, rudinelicarvalho@bol.com.br 


\begin{abstract}
plants in the trays, a looping was proceeded in order to remove the undesirable plants, removing the precocious plants in the low vigor lot and the delayed plants in the high vigor lot, intending to use the emerged plants of the day with higher frequencies of emergency on each one of the vigor levels. The transplant was carried out 20 days after sowing. The experiment was developed by a randomized complete block design, with 3 repetitions. It was evaluated: the plants height at 60 DAT, number of panicles per plant at 115 DAT, number of tiller at 60 DAT, leaf area, number of grains per panicle, number of grains per plant, weight of 1000 seeds and plant yield. Seeds of high vigor originated plants with better performance on all evaluations, independing ong the seedline distribuition. The use of high vigor seeds on the establishment of hybrid rice populations provided increases over than $30 \%$ on the yield.
\end{abstract}

Terms of indexation: Oryza sativa, vigor, arrangement.

\section{INTRODUÇÃO}

No Brasil, o arroz é o terceiro produto agrícola mais importante depois da soja e do milho, tendo produzido na última safra de 2007/2008, aproximadamente 12 milhões de toneladas (CONAB, 2008). O Rio Grande do Sul ocupa um lugar de destaque na cultura, respondendo por $50 \%$ da produção nacional e $80 \%$ do arroz irrigado. O desafio para alcançar altos padrões de qualidade e de produtividade compatíveis com as crescentes necessidades de alimento do planeta é, talvez, a principal explicação para a expansão do arroz híbrido.

$\mathrm{O}$ vigor das sementes modifica o desenvolvimento vegetativo e está freqüentemente relacionado ao rendimento em culturas que são colhidas no estádio vegetativo ou durante o inicio do desenvolvimento reprodutivo. Várias pesquisas mostram influência do vigor das sementes também no rendimento de grãos nas culturas. Em milho, pode ocorrer até $8 \%$ de redução na produtividade com a utilização de sementes de baixo vigor (Grabbe, 1966). Kolchinski (2003) observou redução de $28 \%$ no rendimento de grãos em função da variação do vigor de sementes em populações de soja. Schuch e Finatto (2006), em experimento com comportamento de plantas isoladas de soja, observaram redução do rendimento em função da variação de vigor de sementes. Em arroz irrigado, comunidades de plantas originadas de sementes de alto vigor apresentam rendimento superior a $20 \%$ em relação às comunidades de plantas originadas de sementes de baixo vigor (Melo et al., 2006).

A competição entre plantas tem sido assunto de pesquisa há muitos anos. No entanto, são escassos os trabalhos que estudam os efeitos devidos aos diferentes níveis de vigor entre as sementes dentro de um lote, sobre a uniformidade na emergência, o tamanho inicial das plântulas, a taxa de crescimento da cultura, a posterior competição intraespecífica, rendimento de sementes das plantas individuais dentro das comunidades, e o comportamento geral das comunidades (Kolchinski et al., 2005). Embora seja conhecido o efeito da competição de plantas dentro de populações, não estão mensurados os efeitos do vigor de sementes na competição de plantas em uma comunidade de arroz irrigado (Melo, 2005).

Trabalho realizado por Merotto Júnior et al.,(1999) também demonstram que ocorre competição entre plantas dentro de comunidades, em que as plantas mais desenvolvidas apresentam vantagem na competição intra-específica. O trabalho Merotto Júnior et al.,(1999) utilizou à metodologia de variação na data de semeadura, em covas adjacentes na linha de semeadura, para produzir a desuniformidade na emergência. Em milho, os autores observaram que as plantas que emergiram tardiamente foram dominadas, e ocorreu uma compensação por parte das plantas que emergiram primeiro. No entanto, a compensação não foi suficiente para proporcionar rendimento de grãos semelhante ao de uma comunidade com emergência uniforme.

As respostas das plantas à competição por luz incluem mudanças na arquitetura da planta, no crescimento e desenvolvimento, na absorção e distribuição de assimilados (Almeida \& Mundstock, 1998). Ao analisarem a influência de quatro níveis de radiação solar $(30,50,70,100 \%)$ em plantas de soja, (Menges et al., 1989) observaram que as taxas de crescimento da cultura diminuíram com a redução da radiação solar, ocasionadas por menores áreas foliares das plantas originadas.

O trabalho teve como objetivo avaliar o comportamento individual de plantas de arroz híbrido originadas de sementes 
de alto e de baixo vigor em populações constituídas de diferentes combinações de distribuição dessas plantas ao longo da linha de semeadura.

\section{MATERIAL E MÉTODOS}

O experimento foi realizado na Área Experimental e Didática do Departamento de Fitotecnia da Faculdade de Agronomia Eliseu Maciel (FAEM) da Universidade Federal de Pelotas. Foram utilizadas sementes de arroz do híbrido Avaxi da empresa RiceTec ${ }^{\circledR}$, de dois lotes devidamente caracterizados como de alto e de baixo vigor. $\mathrm{Na}$ caracterização inicial dos lotes de sementes de arroz híbrido, o lote de alto vigor apresentou germinação de $97 \%$, o teste de frio $88 \%$ e o envelhecimento acelerado de $93 \%$. O lote de baixo vigor apresentou germinação de $83 \%$, o teste de frio $62 \%$ e o envelhecimento acelerado $67 \%$.

A semeadura de cada lote foi realizada em bandejas distintas com solo como substrato, a uma profundidade de $2,5 \mathrm{~cm}$ para posterior transplante das plantas para o campo. Após a emergência das plântulas foi realizado um desbaste nas bandejas, retirando as plantas mais precoces no lote de baixo vigor e as plântulas mais tardias no lote de alto vigor, com o propósito de utilizar as plântulas emergidas no dia de maior freqüência de emergência em cada um dos níveis de vigor.

O transplante foi realizado aos 20 dias após a semeadura, momento em que as plantas estavam no estádio V3 com estatura de 10-12 cm, de acordo com as Recomendações Técnicas para o Arroz Irrigado, SOSBAI (2007). No transplante foi utilizado uma distância entre linhas de $20 \mathrm{~cm}$ e espaçamento entre plantas de $3 \mathrm{~cm}$, com 33 plantas por metro linear e população de 166,7 planta por $\mathrm{m}^{2}$.

Os tratamentos constaram de cinco arranjos de plantas constituídas por combinações de distribuição de plantas originadas de sementes de alto (A) e baixo vigor (B), transplantadas ao longo da linha de semeadura. Os arranjos das plantas foram os seguintes:

a) Arranjo 1- AAAA (100\%)- todas as plantas da linha de semeadura com sementes de alto vigor; b) Arranjo 2BAAA (75\%)- três plantas originadas de sementes de alto vigor e uma de baixo vigor ao longo da linha de semeadura; c) Arranjo 3 - $\mathrm{ABAB}$ (50\%)- uma planta originada de sementes de alto vigor e outra de baixo vigor ao longo da linha de semeadura; d) Arranjo 4 - ABBB (25\%)- uma planta originada de sementes de alto vigor e três de baixo vigor ao longo da linha de semeadura; e) Arranjo 5 - BBBB (0\%)todas as plantas da linha de semeadura com sementes de baixo vigor. Cada linha de semeadura possuía quatro metros de comprimento, e estavam perfeitamente identificadas as plantas originadas de sementes de alto e baixo vigor em cada arranjo de plantas.

A correção da fertilidade foi realizada de acordo com análise de solo baseados nas recomendações da Rolas (1994), sendo incorporado no solo o adubo NPK na semeadura. A adubação nitrogenada dividida em três aplicações: 1/3 antes da entrada de água, $1 / 3$ na diferenciação do primórdio floral e $1 / 3$ no florescimento. Não foi necessário tratamento fitossanitário. O controle das plantas daninhas foi realizado manualmente, o mais precoce possível para evitar o efeito da competição inter e intra-específica na comunidade.

Por ocasião da maturação das plantas que ocorreu aos 115 dias após transplante (DAT), coletaram-se 20 plantas originadas de sementes de alto e baixo vigor e de cada localização dentro dos distintos arranjos de plantas, para a determinação dos diversos parâmetros avaliados, mantendo separadamente cada planta para a avaliação do comportamento dessas plantas.

Foi avaliada a estatura das plantas $(\mathrm{cm})$ na maturação, aos 115 dias após o transplante (DAT), e também a área foliar, o número de panículas por planta, o número de grãos por planta, o número de grãos por panícula por planta e a produção de grãos por planta (g).

A estatura de plantas foi avaliada com régua graduada. Foi utilizado um determinador de área foliar Licor LI2600 do Laboratório Didático de Análise de Sementes da Universidade Federal de Pelotas. As panículas de cada planta foram trilhadas manualmente e levados ao secador onde se obteve a umidade média final de $13 \%$, a qual foi determinada pelo método de estufa a $105^{\circ} \mathrm{C}$ por 24 horas (BRASIL, 1992). Após secagem, foi realizada pesagem, utilizando balança centesimal para se obter o rendimento de grãos por planta.

O delineamento experimental utilizado foi de blocos ao acaso com três repetições. $\mathrm{O}$ experimento apresentou uma área de $100 \mathrm{~m}^{2}$, considerando também o efeito da bordadura lateral e de extremidade nas linhas. $\mathrm{Na}$ execução das análises estatísticas para o comportamento individual dentro de populações de arroz híbrido, a análise de variância foi realizada pelo teste $\mathrm{F}$ a $5 \%$ e, quando significativo, executouse comparação de médias pelo teste de Scott-Knott, com nível de probabilidade de 5\%. A execução das análises para o comportamento de populações de arroz híbrido em função das proporções de plantas originadas de sementes de alta e baixa qualidade fisiológica, os dados experimentais foram submetidos à análise de variância utilizando o nível de $5 \%$ de significância, enquanto que o desempenho das comunidades 
foi avaliado por regressões polinomiais

\section{RESULTADOS E DISCUSSÃO}

O desempenho de plantas originadas de sementes de alto e baixo vigor conforme sua distribuição na população apresentou significância estatística entre os tratamentos para vários parâmetros de avaliação utilizados.

Os resultados obtidos nas avaliações do comportamento individual dentro de populações de arroz híbrido em função das proporções de plantas originadas de sementes de alta e baixa qualidade fisiológica na linha de semeadura mostraram superioridade das sementes de alto vigor nos parâmetros avaliados. Para variável área foliar (Figura 1), plantas de arroz híbrido oriundas de sementes de alto vigor foram superiores em relação aquelas oriundas de sementes de baixo vigor. Isso foi constatado também por Melo (2005) ao observar em três épocas de avaliação uma superioridade das plantas originadas de sementes de alto vigor sobre as plantas oriundas de sementes de baixo vigor. Kolchinski (2003), ao avaliar o comportamento individual de plantas em comunidades de soja, também observou que plantas provenientes de sementes de alto vigor apresentaram maiores índices de área foliar na floração em relação às plantas provenientes das sementes com baixo vigor. Efeitos do vigor das sementes sobre a área foliar também foram constatados em outros trabalhos que avaliaram o efeito de qualidade de sementes sobre as comunidades resultantes (Schuch, 1999; Machado, 2002; Höfs, 2003).

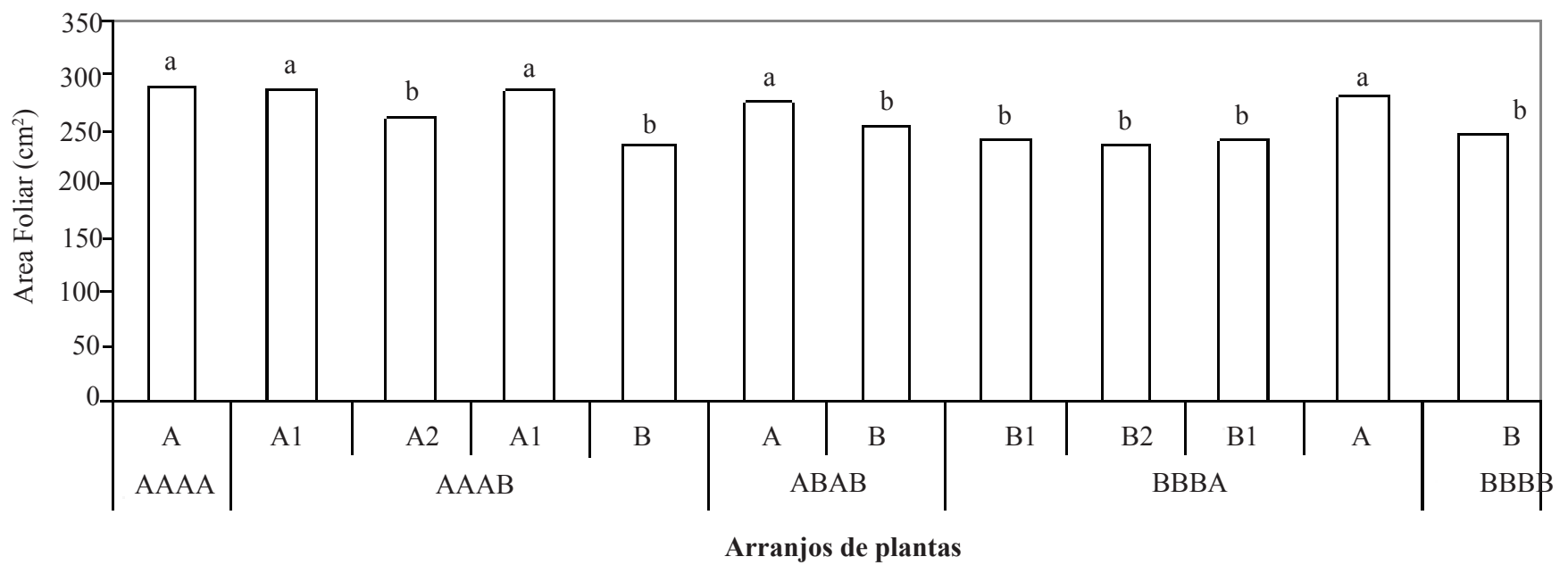

FIGURA 1. Área Foliar das plantas individuais de arroz híbrido dentro das comunidades constituídas pelos diferentes arranjos de plantas. Capão do Leão, RS . A-Plantas originadas de sementes de alto vigor dentro do arranjo de plantas. B-Plantas originadas de sementes de baixo vigor dentro do arranjo de plantas. A1-Plantas originadas de sementes de alto vigor dentro do arranjo de plantas, localizadas imediatamente ao lado das plantas originadas de baixo vigor. A2-Plantas originadas de sementes de alto vigor dentro do arranjo de plantas, localizadas entre duas plantas de alto vigor. B1-Plantas originadas de sementes de baixo vigor dentro do arranjo de plantas, localizadas imediatamente ao lado das plantas originadas de alto vigor. B2Plantas originadas de sementes de baixo vigor dentro do arranjo de plantas, localizadas entre duas plantas de baixo vigor. Médias com mesma letra não diferem pelo teste de Scott-Knott a 5\% de probabilidade.

Trabalhando com emergência e crescimento de plântulas de arroz irrigado, Höfs et al. (2004) observaram que a área foliar também foi menor com o uso de sementes de menor qualidade fisiológica. Na avaliação do crescimento inicial de plantas de soja, Kolchinki et al. (2006), constataram que as plantas provenientes das sementes de alto vigor apresentaram áreas foliares superiores às plantas provenientes das sementes de baixo vigor.
O número de panículas por planta (Figura 2), rendimento de grãos (Figura 3), número de grãos por panículas (Figura 4), número de grãos por planta (Figura 5) seguiram a tendência das demais variáveis, com nítida superioridade das plantas originadas de sementes de alto vigor sobre as plantas de baixo vigor. Comportamento semelhante também foi observado por Melo et al. (2006) com arroz irrigado e Kolchinski (2003) com soja. 


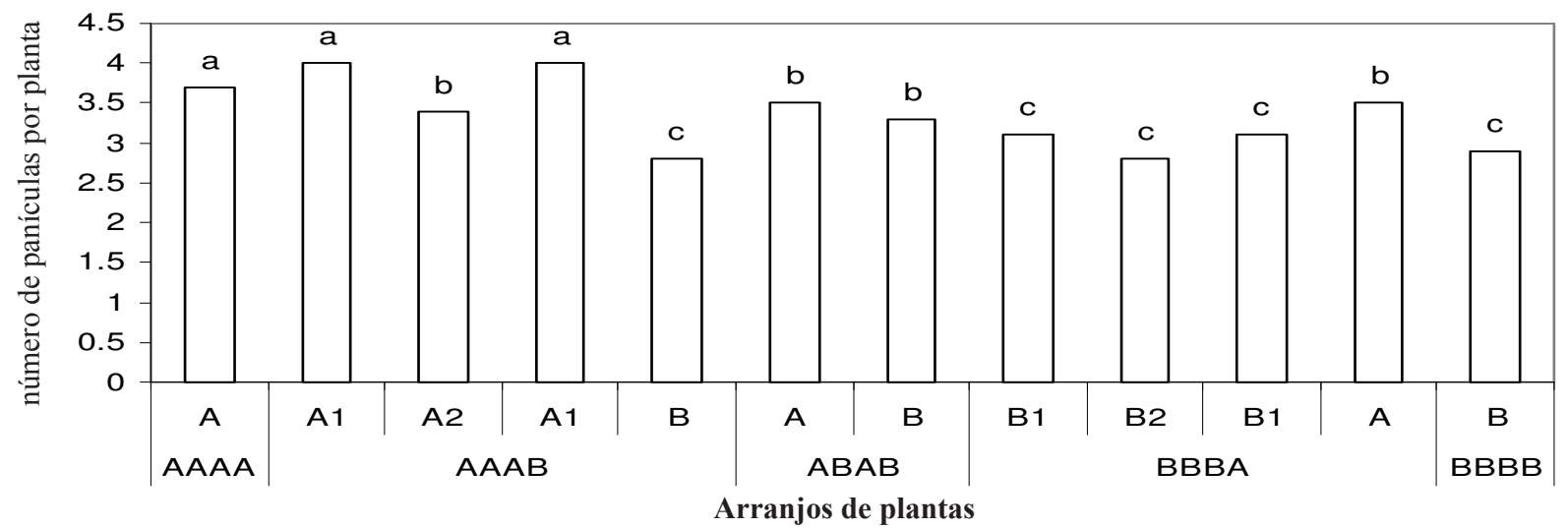

FIGURA 2. Número de panículas das plantas individuais de arroz híbrido dentro das comunidades constituídas pelos diferentes arranjos de plantas. Capão do Leão. A-Plantas originadas de sementes de alto vigor dentro do arranjo de plantas. B-Plantas originadas de sementes de baixo vigor dentro do arranjo de plantas. A1Plantas originadas de sementes de alto vigor dentro do arranjo de plantas, localizadas imediatamente ao lado das plantas originadas de baixo vigor. A2-Plantas originadas de sementes de alto vigor dentro do arranjo de plantas, localizadas entre duas plantas de alto vigor. B1-Plantas originadas de sementes de baixo vigor dentro do arranjo de plantas, localizadas imediatamente ao lado das plantas originadas de alto vigor. B2-Plantas originadas de sementes de baixo vigor dentro do arranjo de plantas, localizadas entre duas plantas de baixo vigor. Médias com mesma letra não diferem pelo teste de Scott-Knott a 5\% de probabilidade.

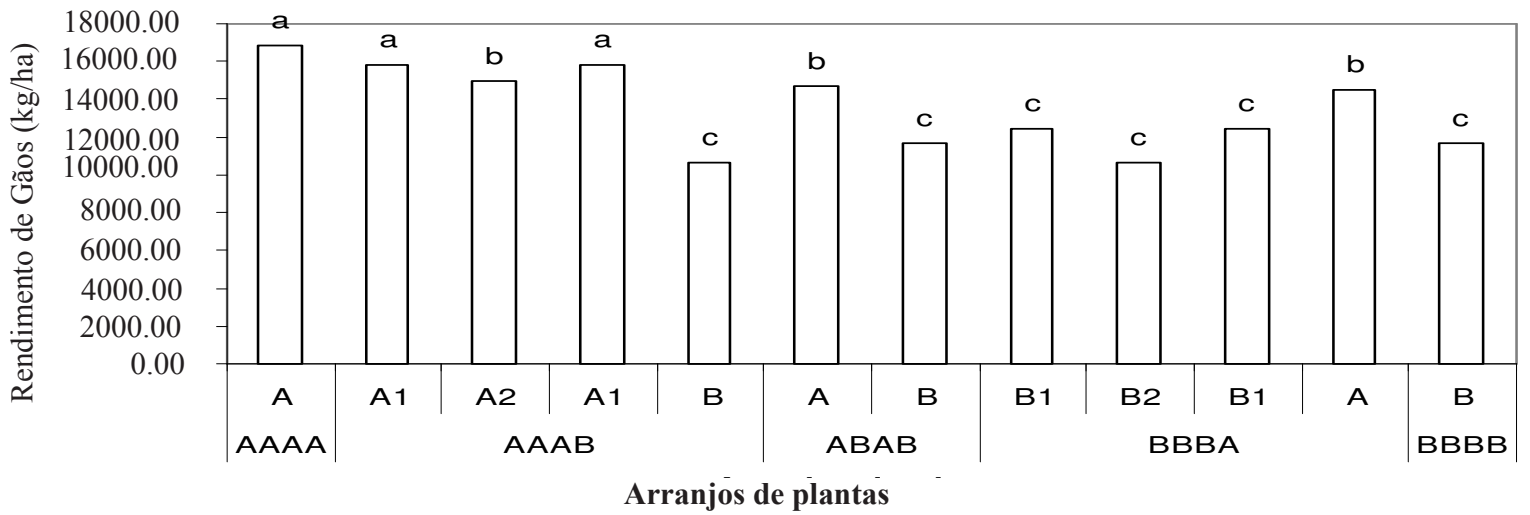

FIGURA 3.Rendimento de grãos (Kg.ha-1) das plantas individuais de arroz híbrido dentro das comunidades constituídas pelos diferentes arranjos de plantas. Capão do Leão, RS. A-Plantas originadas de sementes de alto vigor dentro do arranjo de plantas. B-Plantas originadas de sementes de baixo vigor dentro do arranjo de plantas. A1-Plantas originadas de sementes de alto vigor dentro do arranjo de plantas, localizadas imediatamente ao lado das plantas originadas de baixo vigor. A2-Plantas originadas de sementes de alto vigor dentro do arranjo de plantas, localizadas entre duas plantas de alto vigor. B1-Plantas originadas de sementes de baixo vigor dentro do arranjo de plantas, localizadas imediatamente ao lado das plantas originadas de alto vigor. B2-Plantas originadas de sementes de baixo vigor dentro do arranjo de plantas, localizadas entre duas plantas de baixo vigor. Médias com mesma letra não diferem pelo teste de ScottKnott a 5\% de probabilidade. 


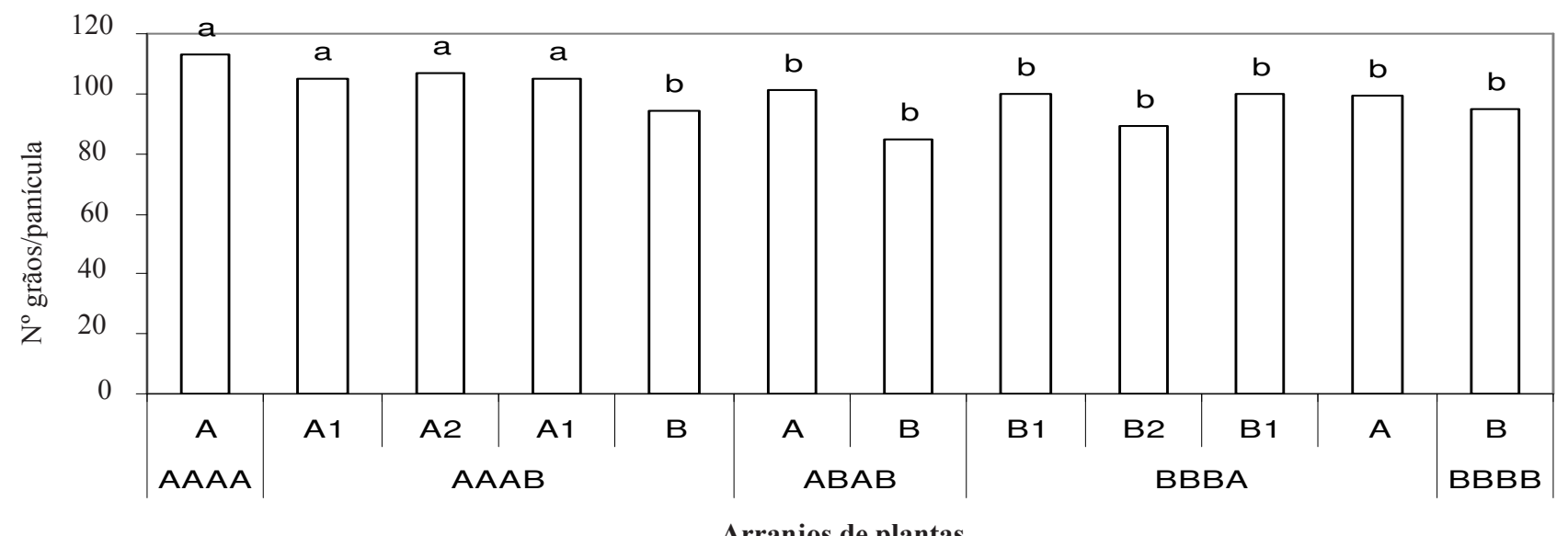

FIGURA 4. Número de grãos por panícula das plantas individuais de arroz híbrido dentro das comunidades constituídas pelos diferentes arranjos de plantas. Capão do Leão, RS. A-Plantas originadas de sementes de alto vigor dentro do arranjo de plantas. B-Plantas originadas de sementes de baixo vigor dentro do arranjo de plantas. A1-Plantas originadas de sementes de alto vigor dentro do arranjo de plantas, localizadas imediatamente ao lado das plantas originadas de baixo vigor. A2-Plantas originadas de sementes de alto vigor dentro do arranjo de plantas, localizadas entre duas plantas de alto vigor. B1-Plantas originadas de sementes de baixo vigor dentro do arranjo de plantas, localizadas imediatamente ao lado das plantas originadas de alto vigor. B2-Plantas originadas de sementes de baixo vigor dentro do arranjo de plantas, localizadas entre duas plantas de baixo vigor. Médias com mesma letra não diferem pelo teste de ScottKnott a 5\% de probabilidade.

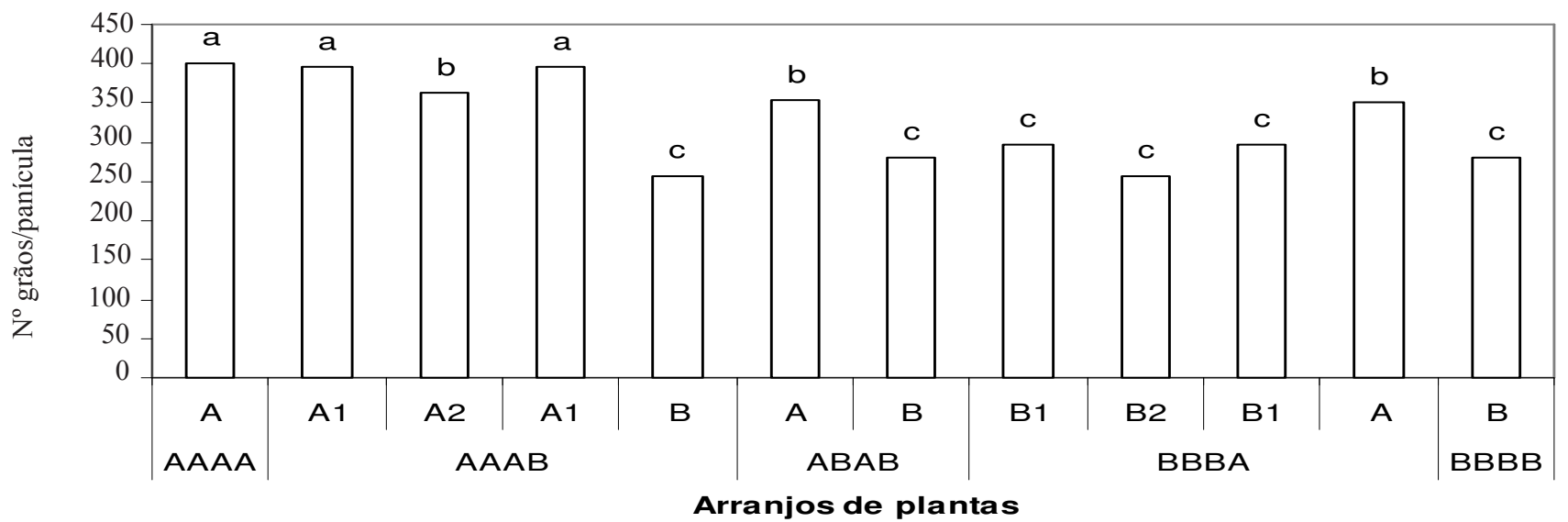

FIGURA 5. Número de grãos por planta individual de arroz híbrido dentro das comunidades constituídas pelos diferentes arranjos de plantas. Capão do Leão, RS. A-Plantas originadas de sementes de alto vigor dentro do arranjo de plantas. B-Plantas originadas de sementes de baixo vigor dentro do arranjo de plantas. A1-Plantas originadas de sementes de alto vigor dentro do arranjo de plantas, localizadas imediatamente ao lado das plantas originadas de baixo vigor. A2-Plantas originadas de sementes de alto vigor dentro do arranjo de plantas, localizadas entre duas plantas de alto vigor. B1-Plantas originadas de sementes de baixo vigor dentro do arranjo de plantas, localizadas imediatamente ao lado das plantas originadas de alto vigor. B2-Plantas originadas de sementes de baixo vigor dentro do arranjo de plantas, localizadas entre duas plantas de baixo vigor. Médias com mesma letra não diferem pelo teste de Scott-Knott a 5\% de probabilidade 
A produtividade das plantas de sementes originadas de sementes de alto vigor mostrou-se significativamente superior em relação às plantas originadas de sementes de baixo vigor do arranjo (Figura 5). A produtividade das plantas originadas de sementes de baixo vigor é menor independentemente do arranjo, entretanto a produtividade das plantas originadas de sementes de alto vigor expressa maior produção quando estão uniformes, tendendo a diminuir quando intercaladas com plantas originadas de sementes de baixo vigor.

Os resultados obtidos nas avaliações do comportamento de populações de arroz híbrido em função das proporções de plantas originadas de sementes de alta e baixa qualidade fisiológica na linha de semeadura mostraram superioridade das sementes de alto vigor com o aumento na proporção das plantas originadas das sementes de alto vigor na população. O número de grãos por panícula (Figura 6), número de grãos por planta (Figura 7) e o rendimento de grãos (Figura 8) mostraram efeito linear crescente, com o aumento da proporção de plantas originadas de sementes de alto vigor. Constatam-se acréscimos no rendimento de grãos superiores a $30 \%$ entre populações constituídas somente por plantas originadas de sementes de baixo vigor e ao analisar quantitativamente o efeito da proporção de plantas originadas de sementes de alto vigor numa população, constata-se em uma estreita relação com o número de grãos por planta e o rendimento (Figura 7 e 8), apresentando uma relação positiva linear, em que o coeficiente de determinação de 0.74 , explica $74 \%$ da variação dos dados em função do vigor de sementes.

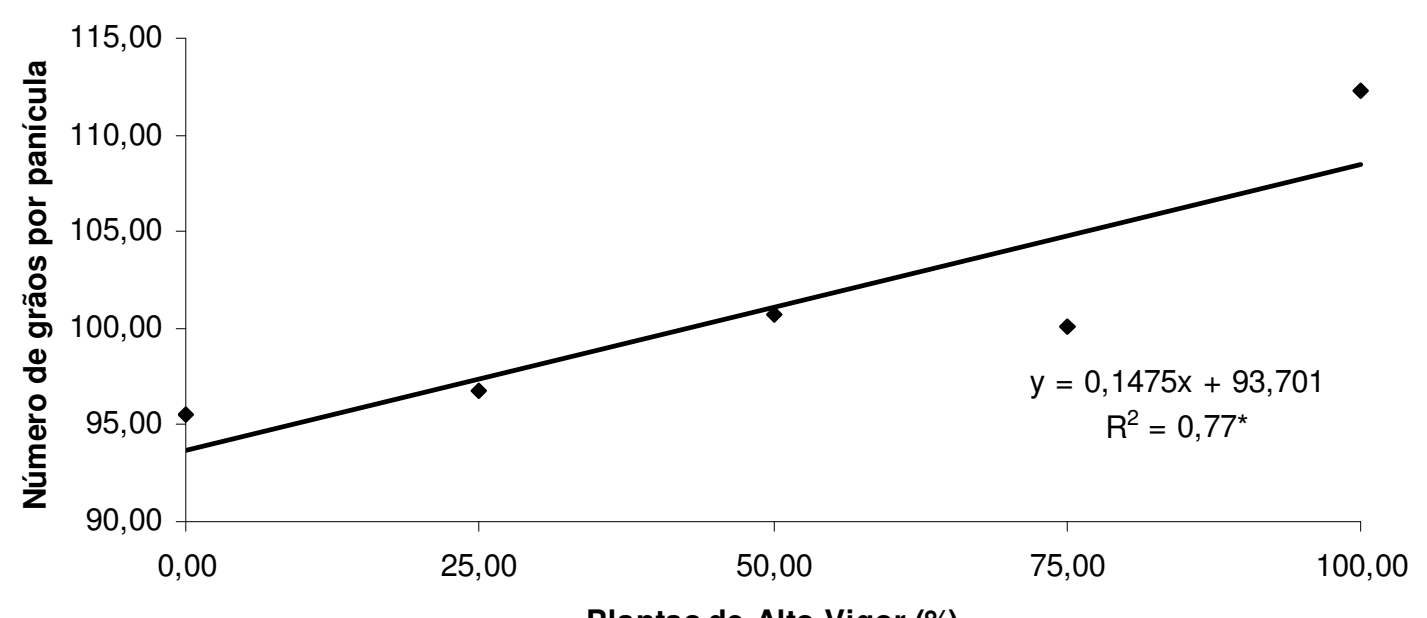

FIGURA 6. Número de grãos por panícula de plantas componentes de comunidades de arroz híbrido, compostas por diferentes proporções de plantas originadas de sementes de alto vigor. UFPel-FAEM, Capão do Leão-RS, 2007.

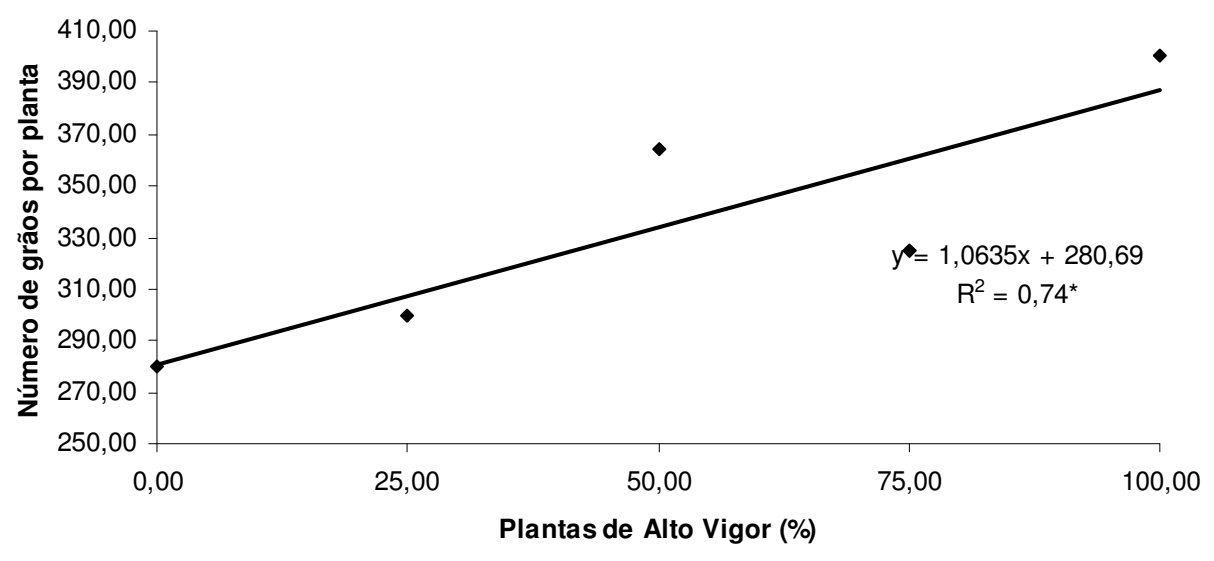

FIGURA 7. Número de grãos por planta de comunidades de arroz híbrido, compostas por diferentes proporções de plantas originadas de sementes de alto vigor. UFPel-FAEM, Capão do Leão-RS, 2007. 


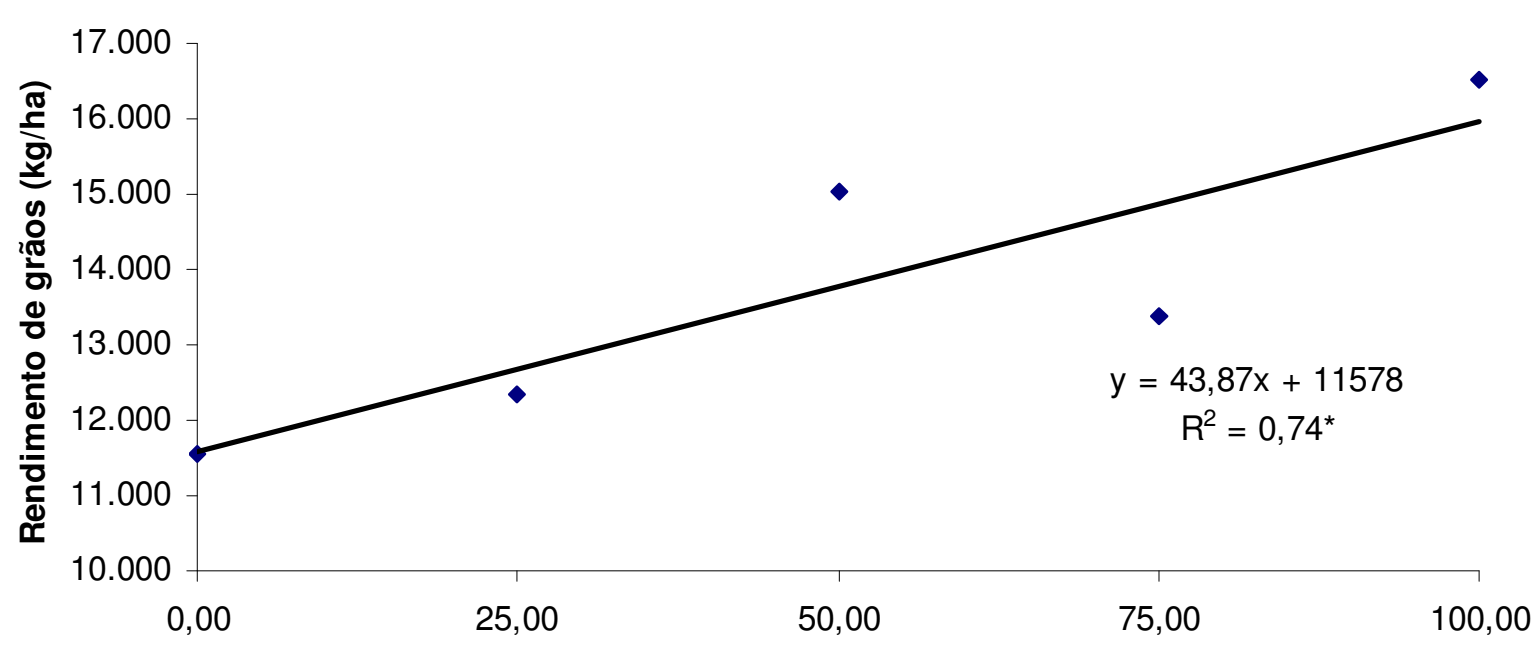

Plantas de Alto Vigor (\%)

FIGURA 8. Rendimento de grãos (Kg/ha), de comunidades de plantas de arroz híbrido, compostas por diferentes proporções de plantas originadas de sementes de alto vigor. UFPel-FAEM, Capão do Leão-RS, 2007.

Os menores rendimentos observados neste trabalho, devido à redução na proporção das sementes de alto vigor, ocorreram porque as plantas originadas de sementes de baixo vigor apresentaram menor produção e não ocorreu efeito compensatório por parte das plantas originadas de sementes de alto vigor. Ao trabalhar com semeaduras de milho em datas diferentes, ao longo da linha de semeadura, Merotto Junior et al. (1999) constataram que as plantas que emergem tardiamente são dominadas pelas plantas de alto vigor, acontecendo uma compensação por parte das plantas que emergem primeiro, embora essa compensação não tenha sido suficiente para proporcionar um rendimento de grãos semelhante ao da comunidade com emergência uniforme.

\section{CONCLUSÕES}

1 - Plantas de arroz híbrido originadas de sementes de alto vigor apresentam desempenho superior em relação às originadas de sementes de baixo vigor quando avaliados individualmente para os parâmetros de área foliar, estatura, número de panículas por planta, produção de grãos, número de grãos por panículas, número de grãos por planta independentemente do arranjo das plantas ao longo da linha de semeadura.

2 - Aumentos na proporção de plantas originadas de sementes de alto vigor, no estabelecimento das comunidades de plantas de arroz híbrido, proporcionam acréscimos no número de grãos por panícula, número de grãos por planta e rendimento de grãos.

3 - O uso de sementes de alto vigor no estabelecimento de comunidades de arroz híbrido proporciona acréscimos $30 \%$ superior na produção de grãos, em relação ao uso de sementes de baixo vigor.

\section{REFERÊNCIAS}

ALMEIDA, A.A.; MUNDSTOCK, C.M. Afilhamento em comunidades de cereais de estação fria é afetado pela qualidade da luz? Ciência Rural, Santa Maria, v.8, n.3, p.511-519, 1998.

BRASIL. Regras para análises de sementes. Brasília, $p$ 183-186, 1992.

CONAB. Arroz - Rio Grande do Sul: área plantada e produtividade: safras 2005/2006. Brasília,2008. Disponível:http://www.conab.gov.br/conabweb/download/ safra/ArrozSerieHist.xls. Acesso em: 08/05/ 2008.

GRABE, D.F. Significance of seedling vigor em corn. Proc. Twenty- first Annual Hybrid Corn Industry- Research Conference, n.21, p.39-44, 1966.

HÖFS, A.; SCHUCH, L.O.B.; PESKE, S.T.; BARROS, A.C.S.A. Efeito da qualidade fisiológica das sementes e da densidade de semeadura sobre o rendimento de grãos e qualidade industrial de arroz. Revista Brasileira de Sementes, Pelotas, v.26, n.2, p.55-62, 2004.

HÖFS, A. Emergência e crescimento de plântulas de arroz em resposta à qualidade fisiológica das sementes. 2003. 44f. Tese (Doutorado em Ciência e Tecnologia de Sementes) - Faculdade de Agronomia Eliseu Maciel, Universidade Federal de Pelotas, Pelotas, 2003. 
HÖFS, A.; SCHUCH, L.O.B.; PESKE, S.T.; BARROS, A.C.S.A. Efeito da qualidade fisiológica das sementes e da densidade de semeadura sobre o rendimento de grãos e qualidade industrial em arroz. Revista Brasileira de Sementes, Pelotas, vol. 26, n.2, p.55-62, 2004.

KOLCHINSKI, E.M. Vigor de sementes e competição intraespecífica em soja. 2003. 44f. Tese (Doutorado em Ciência e Tecnologia de Sementes) - Faculdade de Agronomia Eliseu Maciel, Universidade Federal de Pelotas, Pelotas, 2003.

KOLCHINSKI, E.M.; SCHUCH, L.O.B.; PESKE, S. T. Vigor de sementes e competição intra-específica em soja. Ciência Rural, Santa Maria, v.35, n.6, p.1248-1256, 2005.

KOLCHINSKI, E. M.; SCHUCH, L.O.B.; PESKE, S.T. Crescimento inicial de soja em função do vigor das sementes. Revista Brasileira de Agrociência, v. 12, n. 2, p. 163-166, 2006.

MACHADO, R.F. Desempenho de aveia-branca (Avena sativa L.) em função do vigor de sementes e população de plantas. Pelotas, 2002. 46f Dissertação (Mestrado em Ciência e Tecnologia de Sementes - Faculdade de Agronomia Eliseu Maciel-UFPel, 2002.

MELO, P.T.B.S. Desempenho individual e de populações de plantas de arroz relacionado ao vigor de sementes. Pelotas, 2005. Tese (Doutorado em Ciência e Tecnologia de Sementes) - Faculdade de Agronomia Eliseu Maciel, UFPel, Pelotas, 2005.

MELO, P.T.B.S.; SCHUCH, L.O.B.; ASSIS, F.N; CONCENÇO,G. Comportamento Individual de plantas originadas de sementes com diferentes níveis de qualidade fisiológica em populações de arroz irrigado. Revista
Brasileira de Sementes, v.28, n.2, p.84-94, 2006.

MENGES, E.A.; LOPES, N.F.; OLIVA, M.A. Crescimento e conversão de energia solar em soja cultivada sob quatro níveis de radiação solar. Pesquisa Agropecuária Brasileira, Brasília, v.24, n.9, p.1065-1072, 1989.

MEROTTO JUNIOR, A.; SANGOI, L.; ENDER, M. A desuniformidade de emergência reduz o rendimento de grãos de milho. Ciência Rural, Santa Maria, v.29, n.4, p.595-601, 1999.

ROLAS. Recomendações de adubação e calagem para os Estados do Rio Grande do Sul e Santa Catarina. $3^{\text {a }}$ Ed. Passo Fundo, SBCS-Núcleo Regional Sul, 1994. 223p.

SCHUCH, L.O.B. Vigor de sementes e aspectos fisiológicos da produção em aveia preta (Avena strigosa Schreb). 1999. 127f. Tese (Doutorado em Ciência e Tecnologia de Sementes) - Faculdade de Agronomia Eliseu Maciel, Universidade Federal de Pelotas, Pelotas, 1999.

SCHUCH, L.O.B. Maximizando a produção com sementes de alto vigor. Revista SEED News, Pelotas, 2006. p.8-11. Disponível em: <http:// www.seednews.com.br

SCHUCH, L.O.B.; FINATTO, J.A. Comportamento de plantas isoladas de soja em função da qualidade fisiológica das sementes In: XIV Congresso de Iniciação Científica e VII Encontro de Pós-Graduação, 2006, Pelotas: Editora e Gráfica Universitária UFPel, 2006.

SOCIEDADE Sul-Brasileira de Arroz Irrigado. Desenvolvimento da planta de arroz e clima. Recomendações Técnicas da Pesquisa para o Sul do Brasil. Pelotas-RS, p 11-13, 2007. 